Global Conferences Series:

Social Sciences, Education and Humanities (GCSSSEH), Volume 2, 2019

The $2^{\text {nd }}$ International Conference on Sustainable Development \& Multi-Ethnic Society

DOI: https://doi.org/10.32698/GCS.0185

\title{
Instilling Literacy Through Sing-Along Teaching Technique for Enhancing English Vocabulary Development for Marginalized Community
}

\author{
Erlisa Ennie ${ }^{1}$, Anuar Ahmad ${ }^{2}$, Mohd Mahzan Awang ${ }^{3}$ \& Abdul Razaq Ahmad ${ }^{4}$ \\ ${ }^{1234}$ Faculty of Education UKM, MALAYSIA \\ E-mail: alexiserlisa90@gmail.com
}

Received $\operatorname{xxxxxx}$

Accepted for publication $\mathrm{xxxxxx}$

Published $\mathrm{xxxxxx}$

\begin{abstract}
This paper discusses the use of sing-along teaching technique for enhancing English vocabulary development for marginalized community. This paper highlights the importance of sing-along environment for in calculating the student's interest and attention to learn English vocabulary. This is due to past studies that students or pupils will be more motivated to learn something in enjoyable environment especially in learning English vocabulary. The specific aim is to identify on how effectiveness when using songs in teaching vocabulary for English subject. The empirical studies show sing-along teaching technique for enhancing English vocabulary development for marginalized community helps the pupils to be more motivated in learning English.
\end{abstract}

Keywords: sing-along, vocabulary development, marginalized community

\section{Introduction}

Researchers, English as a second language (ESL) teachers, and students have long recognized the importance of vocabulary development as a foundation for second language reading. To illustrate, in order to truly know a word, a learner must be able to (a) define it, (b) decode and spell it, (c) pronounce it, (d) know its multiple meanings (including common and specialized meanings), and (e) be able to ascertain and apply the appropriate meaning in a particular context (Calderon, 2007; Nagy \& Scott). ESL teachers, then, need to carefully target their instruction for maximum impact. In Malaysia, literacy development among the marginalized community in rural place in Sarawak has often been a major concern.

First and foremost, it is essential to understand the teaching methodology by looking into the consideration of their pattern in learning. The learning engagement in class is determined through the understanding of their learning domains, learning style, and the reason to educate the adults of low-proficiency level. It is crucial to investigate their domain which reflects on teaching methodology upon the 
class conducted. According to Bloom's Taxanomy (1956), there are three (3) types of learning domain: cognitive, affective and psychomotor.

Looking into each of the learning domain mentioned by Bloom Taxanomy (1956), cognitive development is referring to the development of their knowledge that was mentally involved. Affective development is looking into their attitude and self-discovery that include emotional and growth in feelings that reflects their beliefs. Whereby psychomotor is refers to their skills development or practical application. Each of the learning domains discussed affects the preparation of lesson plan before conducting the class.

The vocabulary development among the marginalized community back in Sarawak rural area is critical. The lesson carried out among them is also unique as it is crucial to investigate other contributing factors towards learning style. In contrary, the understanding towards how and why learning takes place among the marginalized community is vital as the element of culture is necessary throughout the lesson preparation.

Songs have been widely used to create a languagerich environment (Newham 1995; McMullen and Saffran 2004; Millington 2011), whilst introducing and consolidating a great bulk in vocabulary. Regarding that, Orlova (1997) discusses some other benefits of using songs in language learning which encourage learners to acquire more vocabulary in a language and help students in recognizing words and meanings more easily. The use of English songs in this study seeks to act as a treatment, in order to build confidence and to help those who are reluctant to speak English. The emphasis on the language acquisition of this study is on vocabulary development. In order to enhance vocabulary development, this study uses songs (English songs) to empower students' memorization technique and to get them connected with language exposure by listening to the songs' lyrics.

\section{Problem Statement}

Regardless on the subject matter discussed in the introductory of this study, vocabulary development is afflictive that leads to the understanding the context of text read. Furthermore, it is essential to investigate their language (mother-tongue) to develop the understanding of the text given to the learners. The main root of the problem in the lesson conducted especially among the learners with lowproficiency in English language is how to motivate and what are the motivation factors towards learning and what intervention involved in the classroom while conducting the lesson.
One of the challenges experienced among most teachers in Sarawak, especially those teaching in rural areas, is the transmitting of knowledge in English to students. Also, the students are reluctant to acquire the language due to cultural and mother tongue issues, which makes vocabulary development difficult. Looking at the linguistic background in most Sarawak schools, most students are hesitant to speak in English due to the negative physical response from their friends, rather than being in a multicultural community. Hence, they tend to speak in their mother tongues with friends in their daily conversations. The reality here is that rural areas tend to have lack of exposure to the English language, which leads to impediments in learning; and more research is obviously required on vocabulary learning, in order to enhance vocabulary development, especially among the low-proficiency language learners (Abidin et. al., 2011).

\section{The concept of literacy issues among the marginalized community}

The fundamental aim of this concept paper is to investigate the intervention involved in the classroom and the motivational factors towards learning. It is necessary for English language learners to acquire many words in order to enhance their communication skills (Abidin, PourMohammadi, Singh, Azman, \& Souringyavongsa, 2011). Schmitt (2008) says that learners need the chances to applied vocabulary incidentally where learners can acquire new words casually, without learning deliberately or specifically. In that regards, Dale (1992:5) states that songs are good at introducing vocabulary because songs provide a meaningful context for the vocabulary. The exploration of this study helps in enhancing and reinforcing the learning and teaching English particularly in improving the language learners' vocabulary development.

\subsection{Music and Language Learning}

From the young age, music is central to human life and synonym in most functions and occasions. Music has a sentimental added value in a human experience according to Gardner (1983). In education, music acts as an art which supports learning conduciveness. Hence, by having songs (for singing), it could enhance language acquisition by nurturing students through musical learning (Gardner, 1993). James Ariffin Miseng (2012:78) mentioned that "music is a great motivator of thinking and feeling". To discuss further, research has shown that there is a relationship between music and language that makes learning more joyful based on the generative hierarchies that 'start from a surface structure consisting of patterns of notes or words that make melodies or sentences' (Jourdain 1997:277). Lo and Li (1998) concurred that songs can help students to instrumentally 
develop themselves to the extent that they could change the classroom into a cheerful atmosphere. Therefore, songs, music and rhythm 'have been defined as powerful aids to language learning, memory and recall' (Fonseca-Mora et al. 2011:101) which eventually can help in acquiring more sets of vocabulary.

\subsection{The Ethnic and The Language}

Lun Bawang is one of the tribes in Sarawak and one of the components of the indigenous people collectively known as the so-called "Orang Ulu" which means "the remote people". Their spoken language is called "Lun Bawang" or is known as "buri tau". Unfortunately, it has been influencing badly by the Malay and English language. As for example, one of the lefts out spoken language for "Thank you" is supposedly "mawang niat kuh nemuh" in Lun Bawang but is often being uttered as "Terima kasi nemuh" which is partly being influence by the Malay language, or "Thank you' kuan muh" which is partly being influence by the English language.

On the contrary, Kedayan is known as one of the Malay's component and is also called the Brunei Malay. Even though the Kedayan language is quite similar with the Malay language, some words differ in terms of meaning. For example, the term "makan" in Malay language which means "eat" in English has its unique meaning in Kedayan language. The word "makan" has always refers to a feast as in, "Makan tahun ini" refers to "Annual feast". Other words that has a contrast in meaning between Malay language and Kedayan language which is the term "wang" in Malay which is refers to "money" in English. It is referring to a name, "Awang" when "wang" is the short form of it. In Kedayan language, the term for "money" is called "usin".

\subsection{Hypotheses}

This concept paper is proposing the element of hypotheses from Stephen Krashen. According to Krashen, the ability towards language acquisition is based on the acceptance of knowledge both subconscious and conscious (The Acquisition-Learning Hypotheses). By adapting his theory of language acquisition, it is essential to apply his theory that reflects on the acceptance of English language among the marginalized community. Another theory is based on Monitor Hypotheses that explain further on how acquisition and learning are use. This hypothesis somehow affects the learners learning process because through 'monitor', the accuracy among learners might decrease due to the awareness towards empirical literacy development. In order to observe the learners' reading progress, Krashen suggest that it is crucial to investigate the understanding of comprehensible input that reflects on the selection of songs for the learners. Hence, by looking into the motivational prospect towards the marginalized community is also necessary as it reflects on teaching styles of the learners. Finally, the last hypotheses are a strong connection with the study of this paper; the reading hypotheses in conjunction with the sing-along teaching technique. According to Krashen, the more reading practice through sing-along takes place, the more vocabulary developed by respective learners.

\section{Issues and Problem}

English is being used as the second language in Malaysia. Asmah (1977) mentioned that English was first the official language, and then being revised as a second language. The phenomena of English language among students at the northern-east Sarawak of east Malaysia is that it is taken as a foreign language since the people has their own mother tongue. Due to multi-ethnicity, the Malay language is taken as the secondary importance in the ranking of languages in Sarawak.

\subsection{The Language Phenomena}

The medium of communication among the marginalized community are Lun Bawang and Kedayan. Regarding that, English is taken as a foreign language looking at the phenomenon of English language among most students in Sarawak that was stated in the problem statement of this study. It is learned that one of the boundaries towards English language learning is the interference of mother tongue.

According to Awoniyi (1978), mother tongue is defined as the language which a group of people considered being inhabitants of an area acquired in the early years and which eventually becomes their natural instrument of thought and communication. In simplistic terms, mother tongue can be expressly defined as the language a child is first exposed to irrespective of the language of the parents. Drawing from this viewpoint, the person is defined as a native speaker of the first language, although one may also be a native speaker of more than one language if all the languages were learned without formal education.

\section{Conceptual Framework}

According to Chua (2016), the conceptual framework of this concept paper is to establish a causal relationship where it involves a cause-and-effect situation between the variables involved. This study is regarded as an experimental study that aims at predicting the outcome of the variables involved. Generally, there will be two variables involved in this study: independent variable and dependent variable. Specifically, there are two kinds of independent variables; the treatment and the control variables (Chua, 2016). The treatment 
variable in this study refers to the use of songs in order to see the changes in the dependent variables (vocabulary development). Figure 1 illustrates the conceptual framework of this study.

Figure 1: Conceptual Framework of a qualitative study (Chua,

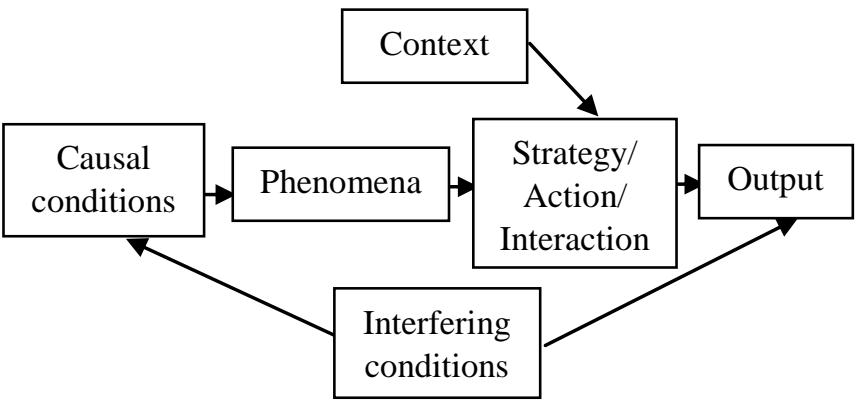

\section{Conclusion}

The purpose of this concept paper is to explore the vocabulary development while reading by having the singalong teaching technique as the intervention to motivate and improving their literacy. First, it is essential to investigate the elements involved in conducting the lesson among the learners of the focused marginalized community in this study as in ways to approach and educating them is one of the challenges faced by the teacher. To hammer away the anxiety to read by building up and enriching their vocabulary is prominent through the lesson carried out during the class session.

Basically, the teacher needs to investigate how they learn the language by looking into three types of learning style according to Malcolm S. Knowles (1996). The three learning styles are according to visual, auditory and kinesthetic. Visual refers to how learners learn by looking, seeing, viewing and watching. Auditory was refers to how learners tend to learn on listening, hearing and speaking. Kinesthetic was based on experiencing, moving and doing.

\subsection{Implication}

Comprehensively, the study of this paper will reveal the pattern of language development among the marginalized community. It is essential to propose Malcolm's (1996) idea on adult learning assumptions: 1) The needs to recognize the purpose of learning, 2) Responsibility towards learning, 3) Experience to learn the language, 4) Readiness in learning, 5) Task-oriented is essential to enhance learning.

\section{References}

[1] Abidin, M.J., Pour-Mohammadi, M., Singh, K.K., Azman, R., \& Souriyavongsa, T. (2011). The Effectiveness of Using Songs in Youtube to Improve Vocabulary Competence among Upper Secondary School Studies. TPLS Theory and Practice in Language Studies, 1(11) doi: 10.4304/tpls.1.11.1488-1496

[2] Chua Y.P (2016) Mastering Research Methods. McGraw Hill Education.

[3] Cresswell J.W (2012) Educational Research: Planning, Conducting and Evaluating Quantitative and Qualitative Research. Pearson Publishers.

[4] Effectiveness of Using Songs in Youtube to Improve Vocabulary Competence among Upper Secondary School Studies. TPLS Theory and Practice in Language Studies, 1(11) doi:10.4304/tpls.1.11.1488-1496.

[5] Fonseca-Mora, C. (2000) 'Foreign language acquisition and melody singing', ELT Journal, vol.54, no. 2, pp. 146152.

[6] Fonseca-Mora, C. Toscano-Fuentes, C. and Wermke, K. (2011) 'Melodies that help: The relation between language and aptitude and musical intelligence', Anglistik International Journal of English Studies, vol. 22, no. 1, pp. 101-118.

[7] Gall, M. D. 2003. Educational Research. Sydney: Pearson Education Inc.

[8] Harmer, J. 2000. The Practice of English language Teaching. London: Longman Group Ltd.

[9] Lefrancois, G. (1994). Psychology for Teaching. Belmont, CA: Wadsworth Publishing Company.

[10] Liu, D. (2004). EFL Proficiency, Gender and Language Learning Strategy Use among a Group of Chinese Technological Institute English Majors. ARECLS EJournal, Vol.1

[11] Lo, R.C. and Li, H.C. (1998) 'Songs enhance learner involvement: Materials development', English Teaching Forum, Retrieved on May 14, 2017 from http://exchanges.state.gov/englishteaching/forum/archive s/1998/docs/98-36-3-b.pdf

[12] McCarthy, M. (1990). Vocabulary. Oxford: Oxford University Press.

[13] McMullen, E. and Saffran, J.R. (2004), 'Music and Language: A developmental comparison', Music Perception, vol. 21, no. 3, pp. 289-311.

[14] Millington, N.T. (2011) 'Using songs effectively to teach English to young learners', Language Education in Asia, vol. 2, no. 1, pp.134-141.

[15] Miseng, J.A (2012) 101 Essential Tips for English Language Teachers, Konsultan Minda Interaktif Publication.

[16] Morales, N. C. (2008). Using Rock Music as a Teaching-Learning Tool. Profile, June 2008. No. 9, p.163-180. 
[17]Orlova, N. (1997). Developing Speech Habits with the

Help of Songs. Retrieved on 21 December, 2016 from www.exchanges.State, gov/forum/vols/vo135/No3/p41.ht

$\underline{\mathrm{m}}$ 